канд. полит. наук, доцент кафедры международных отношений Восточного института - Школь региональных и международных исследований ДВФУ (г. Владивосток)

Электронная почта: zolivnik@mail.ru

\title{
АСЕАН как уникальная модель регионализма
}

Статья представляет собой рецензию на коллективную монографию "Сообщество АСЕАН в современном мире», изданную Центром изучения Вьетнама и АСЕАН Института Дальнего Востока РАН и посвящённую Ассоциации государств Юго-Восточной Азии (АСЕАН) как модели региональной интеграции, её роли и значению в международных отношениях. В рецензии отражены проблемы становления организации и её превращения в актора регионального масштаба, рассмотрена эволюция ассоциации в Сообщество АСЕАН, даётся оценка политическому наследию АСЕАН, а также её отношениям с диалоговыми партнёрами в условиях нарастания противоречий в Юго-Восточной Азии.

Ассоциация государств Юго-Восточной Азии (АСЕАН) является международной организацией, получившей известность не только на региональном, но и на глобальном уровне. Возникнув в период холодной войны на базе Бангкокской декларации, провозгласившей главные цели нового сообщества, касающиеся реализации совместными усилиями регионального сотрудничества в экономической, социокультурной, технической областях, а также в содействии миру и стабильности, АСЕАН встретила полувековой юбилей в статусе успешного интеграционного проекта и ключевого элемента архитектуры безопасности в Азиатско-Тихоокеанском регионе (АТР).

Парадоксальность возникновения АСЕАН состоит не только в том, что организация была создана странами, недавно получившими независимость (за исключением Таиланда) и не имевшими существенного опыта принятия решений на международной арене, но и отсутствием традиции устойчивых союзов и институтов в стратегической культуре Азии [1, с. 74]. Вместе с тем, благодаря коллективным действиям, АСЕАНовцам удалось выдержать испытание временем и воплотить в жизнь уникальный механизм международного сотрудничества, ориентированный на укрепление интеграционных процессов и архитектуры безопасности. Даже несмотря на критику АСЕАН за уязвимость ассоциации к влиянию внешних сил, принцип «асеаноцентичности» (главной роли ассоциации в решении проблем своего региона) остаётся ведущим в условиях растущего противостояния между супердержавами Пацифики: КНР и США - и стремления региональных лидеров: Японии, Индии, Австралии - активизировать внешнеполитическое влияние.

Благодаря своему значению на мировой арене, АСЕАН находится в фокусе научных изысканий отечественных и зарубежных авторов, её деятельности посвящено огромное
Юго-Восточная Азия, ACEAH, интеграция, актор, международная безопасность, международные uнституть, территориальные cnopbl,

Южно-Китайское море
Для изитирования:

Золотухин И. Н. АСЕАН как уникальная модель регионализма // Известия Восточного института. 2020. № 1 . C. 121-127. doi: dx.doi. org/10.24866/2542-1611/2020$1 / 121-127$ 
1 Здесь присутствует аналогия с «европейским концертом», характерной особенностью международных отношений после Венского конгресса (1914-1815), предполагающей баланс сил между европейскими державами путём компромиссов, дипломатических механизмов и коллективных действий.

2 Государствами, подписавшими в августе 1967 г. Бангкокскую декларацию, были Индонезия, Малайзия, Сингапур, Филиппины, Таиланд.

3 Нормы зафиксированы в таких документах, как Куала-Лумпурская декларация о зоне мира, свободы и нейтралитета в ЮВА (1971), Балийский договор о дружбе и сотрудничестве (1976), Бангкокская декларация о создании безъядерной зоны в ЮВА (1995). количество работ. Среди новых публикаций нельзя обойти вниманием выпущенную в прошлом году Центром изучения Вьетнама и ACEAН Института Дальнего Востока РАН коллективную монографию «Сообщество АСЕАН в современном мире» [2], в которой авторы, опираясь на многочисленные источники, исследуют полувековой опыт АСЕАН в поддержании мира и безопасности в АТР, её вклад в развитие экономического сотрудничества и интеграции, а также сотрудничество с диалоговыми партнёрами, в том числе и с Россией. Структурно работа состоит из введения, 12 глав (каждая из которых посвящена конкретному аспекту, начиная с истории возникновения организации и заканчивая её взаимоотношениями с ведущими внешними игроками) и заключения.

В первой главе затронуты перипетии превращения АСЕАН в «концерт государств»1, объединённых общими целями. Зарождение организации происходит в условиях сложной внутриполитической обстановки в странах ЮВА и в эпоху геополитического противостояния, расколовшего регион на линии фронта холодной войны. В этот непростой период страны-основатели ${ }^{2}$ осознавали важность совместных действий как в преодолении региональных проблем и угроз безопасности, так и в создании благоприятной внешней среды для экономического развития. Г. М. Локшин видит серьёзное преимущество ЮВА перед другими регионами мира в цивилизационно-культурном многообразии населяющих её территорию общностей, способных сосуществовать друг с другом [2, с. 20]. Эта особенность дала созидательный импульс процессам интеграции и формированию Сообщества АСЕАН после холодной войны, когда странам ЮВА удаётся создать действенные институты сотрудничества и существенно интенсифицировать отношения друг с другом.

Отдельно отмечается важная роль АСЕАН в выстраивании отношений с макро и внерегиональными игроками. С 1970-х гг. начинается «функциональное расширение» организации [3, p. 33], подразумевавшее создание формата диалоговых партнёрств. В этом шаге проявилась мудрость руководителей АCEAH, понимавших бесперспективность и нереальность отдаления великих держав от региональных процессов. Предложенный ими вариант предполагал заинтересованность внерегиональных игроков в стабильном развитии ЮВА и требовал от них соблюдения норм поведения, принятых в $\mathrm{ACEAH}^{3}$. «Асеаноцентричность» становится базовым принципом «АСЕАНовского концерта», подразумевающим сохранение баланса членов группировки в отношениях с ведущими державами и проявляющимся в деятельности многосторонних структур организации.

В то же время успех АСЕАН в создании новых региональных институтов не снимает с повестки дня вопрос их эффективности, особенно при стойком нежелании членов группировки поступиться своим суверенитетом ради расширения полномочий надгосударственных структур. В этом смысле показателен «метод АСЕАН», предполагающий принятие решений путём достижения консенсуса с учётом всесторонних интересов и уважения позиций всех участников. С другой стороны, акцент членов ассоциации на избегание конфликтов способствовал эволюции АСЕАН в сторону инклюзивности и помог превращению ЮВА из «Азиатских Балкан» в динамично развивающийся регион. 
В следующем блоке монографии рассматривается положение ACЕАН в региональном измерении экономических и политических проблем; соответствующие главы посвящены триединому Сообществу АCЕАН, состоящему из Экономического сообщества (ЭСА), Сообщества политики и безопасности (СПБА) и Социальнокультурного сообщества (СКСА), а также обстановке вокруг территориального конфликта в Южно-Китайском море (ЮКМ).

Сообщество АСЕАН, оформившееся в декабре 2015 г., стало закономерным итогом закрепления эволюционных изменений, происходивших в организации с момента подписания Бангкокской декларации 1967 г. и показавшее неразрывность и взаимосвязь трёх сфер (экономика, безопасность, культура) в укреплении отношений между членами ассоциации и повышения уровня международного сотрудничества АСЕАН. Например, углубление и расширение интеграционных процессов и создание единого экономического пространства предполагает осуществление политических реформ и помогает формированию региональной идентичности; умение превращать конфронтацию в диалог, а соперничество в сотрудничество способствует облегчению экономической кооперации и сближению народов региона; наконец, инициативы по укреплению межкультурного взаимодействия придают прочность институтам АСЕАН.

Важным звеном Сообщества АСЕАН является ЭСА, что во многом объясняется приоритетностью экономических отношений для членов организации. Этот факт повлиял на то, что механизмы экономической интеграции АСЕАН характеризуются наибольшей зрелостью. Секрет успеха экономической интеграции в ЮВА кроется в выгодном географическом положении региона, являющегося центром «золотого треугольника возможностей» (Индия-АСЕАН-Китай), а также в богатых природных и человеческих ресурсах [2, с. 43]. Учитывая разный экономический потенциал участников ассоциации, ими была апробирована модель разноскоростной поэтапной интеграции для обеспечения устойчивого роста и предотвращения рисков.

СПБА АСЕАН возникло как совокупность коллективных решений лидеров ассоциации, направленных на недопущение военных конфликтов в регионе. Заслугой АСЕАН можно считать превращение ЮВА в территорию, где отсутствуют крупномасштабные боевые действия. Осознавая свою уязвимость и хрупкость, особенно в контексте влияния внешних игроков и наличия традиционных и нетрадиционных угроз, страны АСЕАН выработали формат взаимозависимой безопасности, неразрывной друг от друга и как часть общей безопасности региона. Конструктивный опыт АСЕАН в сглаживании региональных противоречий, краеугольным камнем которой является использования «метода АСЕАН», помог организации заслужить кредит доверия со стороны внерегиональных партнёров. СПБА опирается на разветвлённые институты, неофициальные переговорные каналы, структуры «полуторной» и «второй дорожек дипломатии», где происходит регулярное обсуждение проблем безопасности.

В рамках СКСА перед АСЕАНовцами стоит сложная задача выработки коллективной региональной идентичности с учётом высокой степени гетерогенности региона ЮВА. Программы сотрудничества в социально-культурной сфере максимально увязаны с планами развития экономики и региональной безопасности и ориентированы на 
создание сплочённых гармоничных равноправных обществ с растущим уровнем благосостояния. Приоритетное значение в документах СКСА уделяется решению социальных проблем. Позитивный импульс процессу сближения стран и народов региона придаёт развитие культурных обменов и контактов.

В то же время в каждом из сообществ есть проблемы, которые препятствуют достижению синергетического эффекта. Несмотря на продвижение стран АСЕАН по пути укрепления внутрирегионального экономического сотрудничества, сдерживающими факторами интеграции остаются протекционизм, локальные политические конфликты, высокий уровень социального неравенства в странах ЮВА. Дипломатические успехи группировки усилили её ключевую роль в общерегиональных процессах, но АСЕАН критикуется за неспособность влиять на политику отдельных своих членов и за приверженность принципу консенсуса в принятии решений. Некоторые институты СКСА существуют больше на бумаге, а принципы общей социальной политики АСЕАН находятся в стадии формирования и конкретизации.

Кризисной ситуации в ЮКМ посвящено три главы монографии, что говорит об актуальности данной проблемы. За последние 5 лет территориальные противоречия обострились, окончательно перейдя из нормативно-правовой в геополитическую плоскость и поставив под сомнение ведущую роль АСЕАН в формировании новой архитектуры безопасности в ЮВА. Вовлечение в конфликт внерегиональных игроков, таких как США, Япония, Индия, делает неизбежным для АСЕАН совершенствование практики управления рисками посредством приобщения к сотрудничеству крупных держав, заинтересованных в стабильном развитии региона.

В настоящий момент участие АCEAН в решении территориальных споров в ЮКМ по-прежнему выражается в продолжающемся переговорном процессе с КНР и в маневрировании между соперничающими внерегиональными игроками. На первый взгляд, ситуация в ЮКМ показывает ограниченность возможностей АСЕАН в решении проблем, сопряжённых со столкновением национальных интересов, из-за несопоставимости совокупного силового потенциала членов организации и крупнейших внерегиональных участников конфликта. Данный факт объясняет отсутствие у стран ЮВА единой позиции касательно китайских действий, направленных на расширение де-факто контролируемых участков территории в спорных районах, а также рекомендательный характер достигнутых между АСЕАН и КНР договорённостей о поведении сторон в ЮКМ и нежелание АСЕАНовцев вставать на чью-либо сторону в конфликте крупных держав.

В то же время страны ЮВА не готовы становиться пешками в сложной геополитической игре. Прекрасно понимая, что ухудшение положения дел в ЮКМ не будет на руку ни одному из участников конфликта, лидеры АСЕАН продолжают делать шаги по созданию доверительной атмосферы в отношениях с внерегиональными игроками, стремятся снизить накал противоречий вокруг спорных территорий и удержать стороны конфликта в русле конструктивного диалога.

Завершающие главы монографии посвящены отношениям АСЕАН с ведущими диалоговыми партнёрами, такими как КНР, США, Япония, Индия и РФ. 
Сотрудничество АСЕАН с Китаем обусловлено обоюдовыгодностью сохранения мира и безопасности в АТР, несмотря на сложную обстановку в ЮКМ и геополитическую напряжённость в отношениях между ведущими игроками Пацифики. На протяжении последних десятилетий страны ЮВА смогли достичь широкого уровня взаимодействия с Поднебесной, а крупные финансовые вливания Китая в экономику этих стран заставляют их проявлять гибкость в отношениях с северным соседом касательно щекотливых вопросов. С другой стороны, военная мощь Китая и его тенденциозность в отношении территориального спора могут помешать реализации инфраструктурных инициатив Пекина, направленных в том числе на преодоление геополитической уязвимости Китая, для которого важно не только и не столько усилить своё влияние в ЮВА, сколько противостоять влиянию других игроков.

«Стратегический разворот» США в сторону ЮВА и поддержка Вашингтоном принципа «асеаноцентричности» в интеграционных процессах Азии в 2009 г. во многом связаны с противодействием возвышению Китая. Характеризуя американскую политику в отношении ACEAН, авторы сосредоточили внимание на сдерживании Китая как важном элементе выстраиваемой Вашингтоном геополитической конфигурации. В этом отношении американские операции по поддержанию свободы судоходства в ЮКМ - не столько антикитайские провокации, сколько демонстрация силы. Этим же фактом продиктовано инициирование Индо-Тихоокеанской доктрины. Противодействуя Китаю, США стремятся вовлечь страны АСЕАН в реализацию своей стратегии, что ставит под удар принцип «асеаноцентричности» и ведёт к эрозии архитектуры региональной безопасности.

Подчёркивая характер отношений АСЕАН и Японии, авторы обозначают основные векторы регионального сотрудничества страны восходящего Солнца, такие как экономика, безопасность, стратегические вопросы, официальная помощи в целях развития, отмечая важность геоэкономического положения ЮВА для интересов Токио. С другой стороны, стабильная и экономически развивающаяся ЮВА может стать противовесом китайской экспансионистской политике, вызывающей тревогу и озабоченность у Японии. Как страна, стремящаяся усилить влияние в Азии и в результате позиционирующая себя в большей степени как самостоятельный игрок, находящийся в тесной связке в США, нежели марионетка Вашингтона, Япония более чувствительно относится к региональным проблемам, поэтому стремится демонстрировать свою азиатскую идентичность, поддерживает принципы «асеанооцентричности», разделяет позиции стран АCЕАН по международным вопросам.

В отношениях АCЕАН и Индии подчёркивается стремление Нью-Дели усилить присутствие в ЮВА при параллельном следовании принципам «асеаноцентичности». Для Индии важно сохранять имидж сильного и мирного соседа в отношениях со странами ЮВА, одновременно подчёркивая самостоятельность в международных делах. Даже несмотря на наличие нерешённых проблем с Китаем, Индия не намерена участвовать во внешней политике США или Японии, направленной на создание инструментов сдерживания Поднебесной, опасаясь ослабления международного авторитета, что негативно скажется на отношениях со странами АСЕАН. 
Затрагивая особенности сотрудничества России и АСЕАН, авторы обозначают важной сферой отношений между партнёрами обеспечение региональной безопасности, ссылаясь на имеющийся у России мощный военный потенциал, постоянное членство России в СБ ООН и опыт решения международных проблем. В то же время, в отличие, например, от Японии, ставшей экономическим партнёром и примером успешной модернизации для ЮВА ещё в середине прошлого века, и от Индии, с которой у ЮВА есть практика тысячелетнего цивилизационного диалога, Россия по разным причинам только начинает формировать отношения с ЮВА, обладая наиболее тесными связями с Вьетнамом. Среди плюсов сотрудничества между РФ и АСАЕН отмечены развивающееся взаимодействие сторон в формате диалогового партнёрства, а также растущий товарооборот.

Авторы обращают внимание на озабоченность стран АСЕАН рисками и угрозами для существующей конфигурации региональной безопасности, отмечая их сохраняющееся стремление балансировать между Китаем и США. За последние годы, в том числе благодаря США, именно Китай воспринимается странами ЮВА как главный «возмутитель спокойствия» в регионе. Кроме того, большинство АСЕАНовских партнёров, включая Японию и Индию, разделяют подобное восприятие, в отличие от России, придерживающейся некофронтационной повестки и считающей, что американская политика способствует дестабилизации в регионе.

Подведя итоги, авторы отмечают, что перед АСЕАН стоит сложная задача сохранить центральное место в многосторонних региональных отношениях. Нагнетание напряжённости между великими державами способно свести на нет благие начиная организации в деле укрепления сотрудничества и противодействия конфликтам, поэтому лидерам АСЕАН придётся задействовать весь свой уникальный опыт и приложить усилия, чтобы показать торжество разума над эгоизмом национальных интересов.

Монография представляет собой оригинальный интеллектуальный продукт, в котором авторам удалось дать всесторонний анализ потенциалу АСЕАН и показать её роль на международной арене. Работа рекомендована к прочтению всем лицам, интересующимся Юго-Восточной Азией.

\section{Литература}

1. Бордачев Т. В. Что Россия может дать Азии? // Вопросы географии. Сборник 148. Россия в формирующейся Большой Евразии / Ред. В. М. Котляков, В. А. Шупер. - М.: Издательский дом «Кодекс», 2019. 376 c. C. 71-75.

2. Сообщество АСЕАН в современном мире: монография / Г. М. Локшин, Е. В. Кобелев, В. М. Мазырин. - М.: ИД «ФОРУМ»,

2019. 296 c.

3. Khong Y. F., Nesadurai H. E. S. Hanging Together, Institutional Design, and Cooperation in Southeast Asia: AFTA and the ARF // Crafting Cooperation: Regional International Institutions in Comparative Perspective / Edited by A. Acharya, A. I. Johnston. Cambridge: Cambridge University Press, 2007. XII, 318 p. Pp. 32-82. 


\section{Ivan N. ZOLOTUKHIN}

Ph. D. (in Political Science), Assosiate Professor, International Relations Department, Oriental Institute - School of Regional and International Studies, Far Eastern Federal University (Vladivostok, Russia).

E-mail: zolivnik@mail.ru

\section{ASEAN as Unique Model of Regionalism}

The article reviews the book "ASEAN Community in the Modern Southeast Asia, World", published by a group of scholars of the Center for the ASEAN, Vietnam and ASEAN Studies of the Institute of Far Eastern Studies of the Russian Academy of Sciences and dedicated to the Association of Southeast Asian Nations (ASEAN) as a model of regional integration. In the book the role and significance of this organization in international relations is clarified. The review reflects the prerequisites of the formation of the organization, territorial disputes, the main stages of its development and its transformation into the South China Sea. a pivotal actor of regional scale, considers the evolution of the association into the ASEAN Community, assesses the political heritage of ASEAN, as well as its relations with dialogue partners in the face of growing contradictions in Southeast Asia where the rivalry between China as a rising power, expanding its influence in regional issues, and the United States, making great efforts to strengthen their positions, is escalating.

For citation: Zolotukhin I. N. ASEAN as Unique Model of Regionalism // Oriental Institute Journal. 2020. № 1. P. 121-127. doi: dx.doi.org/10.24866/2542-1611/2020-1/121-127

\section{References}

1. Bordachev T. V. CHto Rossiya mozhet dat' Azii? // Voprosy geografii. Sbornik 148. Rossiya v formiruyushhejsya Bol'shoj Evrazii / Red. V. M. Kotlyakov, V. A. SHuper. - M.: Izdatel'skij dom «Kodeks», 2019. 376 s. S. 71-75.

2. Soobshhestvo ASEAN v sovremennom mire: monografiya / G. M. Lokshin, E. V. Kobelev, V. M. Mazyrin. - M.: ID «FORUM»,
2019. $296 \mathrm{~s}$.

3. Khong Y. F., Nesadurai H. E. S. Hanging Together, Institutional Design, and Cooperation in Southeast Asia: AFTA and the ARF // Crafting Cooperation: Regional International Institutions in Comparative Perspective / Edited by A. Acharya, A. I. Johnston. Cambridge: Cambridge University Press, 2007. XII, 318 p. Pp. 32-82. 